\title{
Lung function improvements following inhaled indacaterol/glycopyrronium/ mometasone furoate are independent of dosing time in asthma patients: a randomised trial
}

\author{
Jutta Beier ${ }^{1}$, Henrik Watz ${ }^{2}$, Zuzana Diamant ${ }^{3,4,5}$, Jens M. Hohlfeld $\mathbb{1}^{6,7,8}$, \\ Dave Singh ${ }^{9}$, Pascale Pinot ${ }^{10}$, leuan Jones ${ }^{11}$ and Hanns-Christian Tillmann ${ }^{10}$
}

ABSTRACT Once-daily asthma treatment should prevent night-time deterioration, irrespective of the time of dosing. IND/GLY/MF, a fixed-dose combination of inhaled indacaterol acetate (IND, long-acting $\beta_{2}$-agonist (LABA)), glycopyrronium bromide (GLY, long-acting muscarinic antagonist) and mometasone furoate (MF, inhaled corticosteroid (ICS)) delivered by Breezhaler, is indicated in adult asthma patients inadequately controlled on LABA/ICS.

A randomised, double-blind, placebo-controlled, three-period, crossover, phase II study was performed to investigate the bronchodilator effect of IND/GLY/MF (150/50/80 $\mu \mathrm{g})$ dosed morning and evening versus placebo in patients with mild-moderate asthma. The primary end-point was weighted mean forced expiratory volume in $1 \mathrm{~s}\left(\mathrm{FEV}_{1}\right)$ over $24 \mathrm{~h}$ following 14 days of IND/GLY/MF dosed a.m. and p.m. versus placebo. Secondary end-points included the effect of dosing time on peak expiratory flow (PEF) and safety/tolerability.

Of 37 randomised patients (age 18-72 years; 21 male, 16 female) 34 completed all three treatment periods. At screening, median (range) pre-bronchodilator $\mathrm{FEV}_{1}$ was $75.8 \%$ (60-96\%). Patients were using stable low$(83.8 \%)$ or medium-dose (16.2\%) ICS. Morning and evening dosing of IND/GLY/MF improved FEV (area $^{-}$ under the curve from 0 to $24 \mathrm{~h}$ ) by $610 \mathrm{~mL}(90 \%$ CI $538-681 \mathrm{~mL})$ and $615 \mathrm{~mL}(90 \%$ CI $544-687 \mathrm{~mL})$, respectively, versus placebo. Mean PEF over 14 days increased by $70.7 \mathrm{~L} \cdot \mathrm{min}^{-1}$ (90\% CI 60.5-80.9 L.min ${ }^{-1}$ ) following a.m. dosing, and by $59.7 \mathrm{~L} \cdot \mathrm{min}^{-1}\left(90 \% \mathrm{CI}\right.$ 49.5-69.9 L· $\left.\mathrm{min}^{-1}\right)$ following p.m. dosing of IND/GLY/ MF versus placebo. IND/GLY/MF demonstrated a safety profile comparable with placebo.

Once-daily inhaled IND/GLY/MF was well tolerated and provided sustained lung function improvements over 24 h, irrespective of a.m. or p.m. dosing, in patients with mild-moderate asthma.

@ERSpublications

This randomised study found single-inhaler indacaterol/glycopyrronium/mometasone furoate improved respiratory parameters $\mathrm{FEV}_{1}$ and $\mathrm{PEF}$ in asthma patients, and showed similar efficacy when taken once daily in the morning or evening https://bit.ly/3fH0I1K

Cite this article as: Beier J, Watz $\mathrm{H}$, Diamant $\mathrm{Z}$, et al. Lung function improvements following inhaled indacaterol/glycopyrronium/mometasone furoate are independent of dosing time in asthma patients: a randomised trial. ERJ Open Res 2021; 7: 00425-2020 [https://doi.org/10.1183/ 23120541.00425-2020].

\begin{abstract}
This study is registered at www.clinicaltrials.gov with identifier number NCT03108027 and at www.clinicaltrialsregister.eu with identifier number 2017-000644-17. Novartis is committed to sharing with qualified external researchers, access to patient-level data and supporting clinical documents from eligible studies. These requests are reviewed and approved by an independent review panel on the basis of scientific merit. All data provided is anonymised to respect the privacy of patients who have participated in the trial in line with applicable laws and regulations. This trial data availability is according to the criteria and process described on www.clinicalstudydatarequest.com.
\end{abstract}

This article has supplementary material available from openres.ersjournals.com

Received: 24 June 2020 | Accepted: 14 Nov 2020

Copyright $\odot$ ERS 2021. This article is open access and distributed under the terms of the Creative Commons Attribution Non-Commercial Licence 4.0. 


\section{Introduction}

Despite the availability of combination inhaled corticosteroid (ICS) and long-acting $\beta_{2}$-agonist (LABA) therapies, many patients worldwide are impacted by uncontrolled asthma with clinically relevant symptoms, bronchoconstriction and exacerbations. Inadequately controlled asthma is associated with a poorer quality of life, daily activity limitations, higher risk of exacerbations and a disproportionately high use of healthcare resources $[1,2]$.

The Global Initiative for Asthma (GINA) suggests the addition of a long-acting muscarinic antagonist (LAMA) (tiotropium) for patients with asthma who remain uncontrolled despite treatment with a combination of an ICS with a LABA [3]. There is mounting evidence that add-on LAMA therapy to LABA/ICS can provide additional benefit in terms of fewer exacerbations and improved lung function compared with patients receiving LABA/ICS therapy alone $[4,5]$. Therefore, single-inhaler LABA/LAMA/ ICS fixed-dose combinations are being developed for patients with asthma.

Increased circadian variation is a hallmark of uncontrolled asthma, with symptoms, airway hyperresponsiveness and airway obstruction worsening at night [6]. Airway eosinophils were shown to correlate significantly with circadian rhythm in induced sputum from patients with mild-moderate asthma, with a peak influx at 04:00 h, which also coincided with peak sputum eotaxin concentrations [7]. In addition, there is circadian rhythmic variability in a proportion of exhaled volatile organic compounds over $24 \mathrm{~h}$ [8]. Drugs with a 24-h action should prevent night-time lung function deterioration, irrespective of the time of administration. However, studies have shown that for some inhaled therapies, time of administration can affect drug efficacy over a 24 -h period $[9,10]$.

IND/GLY/MF is an inhaled combination which is approved in the European Union and other countries worldwide, for once-daily treatment of asthma, inadequately controlled by LABA/ICS. This therapy combines sustained bronchodilation by indacaterol acetate (IND, a LABA) and glycopyrronium bromide (GLY, a LAMA) with anti-inflammatory properties of mometasone furoate (MF, an ICS). The fixed-dose combination is delivered with the Breezhaler inhalation device. The Breezhaler device provides feedback on correct delivery [11] and is currently used to deliver a range of medicines in asthma (e.g. budesonide) and COPD, including IND, GLY and IND/GLY.

The aim of this phase II study was to investigate the bronchodilator effect of once-daily inhaled IND/GLY/ MF (150 $\mu \mathrm{g}$ of indacaterol acetate, $50 \mu \mathrm{g}$ of glycopyrronium bromide and $80 \mu \mathrm{g}$ of mometasone furoate (medium dose)) when administered in the morning or in the evening compared with placebo in patients with uncontrolled asthma. The individual components of IND/GLY/MF have demonstrated a sustained 24-h duration of action as mono- or combination therapies [12, 13]. Therefore, we hypothesised that IND/ GLY/MF would demonstrate sustained lung function benefits irrespective of the time of dosing. In addition, the safety and tolerability of the fixed-dose combination versus placebo was evaluated.

\section{Methods}

\section{Participants and study design}

Study participants were males and females with asthma aged $\geqslant 18$ years who were receiving a stable daily regimen of low- or medium-dose ICS (as defined by GINA [14]) for $\geqslant 4$ weeks prior to screening. Eligible patients had a pre-bronchodilator forced expiratory volume in $1 \mathrm{~s}\left(\mathrm{FEV}_{1}\right) \geqslant 60 \%-<100 \%$ of the predicted normal value and demonstrated an $\mathrm{FEV}_{1}$ increase of $\geqslant 12 \%$ and $\geqslant 200 \mathrm{~mL}$ after administration of $400 \mu \mathrm{g}$ salbutamol/360 $\mu \mathrm{g}$ albuterol (or equivalent dose) at screening. Patients who had an asthma exacerbation requiring systemic corticosteroids, hospitalisation or emergency room visit within 1 year prior to the study were excluded. Current smokers and patients who had smoked or inhaled tobacco products within the 6-month period prior to screening, or who had a smoking history of $\geqslant 10$ pack-years, were also excluded. Details of inclusion and exclusion criteria are available in the supplementary material.

Affiliations: ${ }^{1}$ Insaf Respiratory Research Institute, Wiesbaden, Germany. ${ }^{2}$ Pulmonary Research Institute at LungenClinic Grosshansdorf, Airway Research Center North, German Center for Lung Research (DZL), Grosshansdorf, Germany. ${ }^{3}$ Dept of Respiratory Medicine and Allergology, Institute for Clinical Science, Skåne University Hospital, Lund, Sweden. ${ }^{4}$ Dept of Microbiology, Immunology and Transplantation, KU Leuven, Catholic University of Leuven, Leuven, Belgium. ${ }^{5}$ Dept of Clinical Pharmacy and Pharmacology, University of Groningen, University Medical Centre and QPS-NL, Groningen, The Netherlands. ${ }^{6}$ German Center for Lung Research (BREATH), Hannover, Germany. ${ }^{7}$ Dept of Respiratory Medicine, Hannover Medical School, Hannover, Germany. ${ }^{8}$ Fraunhofer Institute of Toxicology and Experimental Medicine, Hannover, Germany. ${ }^{9}$ University of Manchester, Medicines Evaluation Unit, Manchester University NHS Foundation Trust, Manchester, UK.

${ }^{10}$ Novartis Institutes for Biomedical Research, Basel, Switzerland. ${ }^{11}$ Novartis Pharma AG, Basel, Switzerland.

Correspondence: Jutta Beier, Insaf Respiratory Research Institute, Biebricher Allee 34, 65187 Wiesbaden, Germany. E-mail: j.beier@insaf-wi.de 
The study had a randomised, double-blind, placebo-controlled, six-sequence, three-period crossover design and was conducted in six European centres (https://clinicaltrials.gov/ct2/show/NCT03108027) between June 26, 2017 and February 24, 2018. Prior to study enrolment, there was a 14-day screening period, followed by a 14-day unblinded run-in period where patients were instructed to discontinue their previous asthma medications and were provided with short-acting $\beta_{2}$-agonist (SABA; $100 \mu \mathrm{g}$ salbutamol/90 $\mu \mathrm{g}$ albuterol, or another SABA at matching dose strength) as rescue medication. Eligible patients were subsequently randomised to one of the six treatment sequences all consisting of three treatment periods with a minimum duration of 14 days each (maximum 18 days), separated by a 14-21-day washout period (figure 1a). The final treatment period was followed by a study completion evaluation visit after 1-7 days. The total duration of the study was 13-19 weeks for each patient. The study was ended after the last patient completed follow-up.

For the overall relatively short study duration in patients with mild to moderate asthma it was considered acceptable to have a placebo period/control without ICS background. The run-in period made sure that subjects were able to tolerate not taking ICS for a short, defined period of time. Patients who could not tolerate ICS withdrawal were not randomised.

At the end of the run-in period, patients were randomised in a ratio of 1:1:1:1:1:1 (Williams design) to one of six treatment sequences (table 1); each sequence consisted of three double-blind treatment periods of 14-18 days (in different orders) as follows. IND/GLY/MF evening dose (A): placebo (a.m.) and IND/GLY/ MF (p.m.); IND/GLY/MF morning dose (B): IND/GLY/MF (a.m.) and placebo (p.m.); placebo (C): placebo (a.m.) and placebo (p.m.)

The dose strength of IND/GLY/MF administered in this trial was $150 \mu \mathrm{g}$ IND, $50 \mu \mathrm{g}$ GLY and $80 \mu \mathrm{g}$ MF, which is the medium dose of MF delivered with the Breezhaler device (corresponding to MF $400 \mu \mathrm{g}$ delivered with the Twisthaler inhalation device). More information on the study design including treatment sequences and methods is available in the supplementary material.

The patient randomisation list was produced by the interactive response technology provider using a validated system that automated the random assignment of patient numbers to randomisation numbers. All patients gave written informed consent. This study was conducted in accordance with the Declaration of Helsinki and was approved by the independent ethics committees of the participating sites.

\section{Study objectives}

The primary objective of this study was to investigate the effect of dosing time (morning or evening) on the bronchodilator effect of once-daily inhaled IND/GLY/MF (150/50/80 $\mu \mathrm{g}$; medium-dose strength of $\mathrm{MF}$ ) compared with placebo. This was assessed using weighted mean $\mathrm{FEV}_{1}$ over $24 \mathrm{~h}$ (area under the curve from 0 to $24 \mathrm{~h}\left(\mathrm{AUC}_{0-24 \mathrm{~h}}\right)$ ) following 14 days of treatment with IND/GLY/MF dosed in the morning, IND/GLY/MF dosed in the evening, and placebo, as the primary end-point.

Secondary objectives were to evaluate the effect of IND/GLY/MF dosing time on peak expiratory flow (PEF) rate from day 2 to day 14 during the three treatment periods and with serial measurement during the $24 \mathrm{~h}$ spirometry profiling assessment on day 14 of each treatment period. In addition, the safety and tolerability of IND/GLY/MF were assessed.

\section{Study treatment and assessments}

On day 1 of each treatment period, patients attended the site for an outpatient visit in the afternoon $(\sim 1-2 \mathrm{~h}$ before the first scheduled p.m. dose) and day 1 pre-dose assessments were performed. Patients were evaluated for randomisation eligibility (only at treatment period 1) and trained/re-trained on the use of the Breezhaler inhalation device. Patients were instructed to take IND/GLY/MF or placebo in the morning (at $\sim 07: 00 \mathrm{~h}$ ) and in the evening (at $\sim 19: 00 \mathrm{~h}$ ) and to record their pre-treatment morning and evening PEF throughout the study in a patient e-diary.

Spirometry measurements followed the American Thoracic Society/European Respiratory Society guidelines [15]. Patients were provided with a combined electronic PEF-meter and e-diary for recording trough (pre-dose) PEF measurements each morning and evening throughout the entire study. FEV 1 measurements were taken 5 min before the evening dose on day 14 , then $+3 \mathrm{~h},+6 \mathrm{~h},+9 \mathrm{~h},+12 \mathrm{~h},+15 \mathrm{~h}$, $+18 \mathrm{~h},+21 \mathrm{~h}$ and $+23 \mathrm{~h} 55 \mathrm{~min}$ (timing from the day 14 post-evening dose). Spirometry was performed on day 14 prior to and $3 \mathrm{~h}$ after study drug administration and on day 15, 6-12 $\mathrm{h}$ after the last dose of IND/ GLY/MF.

All patients were provided with rescue medication (SABA; $100 \mu \mathrm{g}$ salbutamol/90 $\mu \mathrm{g}$ albuterol or equivalent dose) at day 1 of the run-in period and were instructed to use it on an "as-needed" basis only. SABA use was recorded twice daily throughout the entire study. 
a)

\begin{tabular}{|c|c|c|c|c|c|c|c|c|}
\hline & \multicolumn{2}{|c|}{ Screening } & \multicolumn{5}{|c|}{ Treatment } & \\
\hline & & $\begin{array}{c}\text { Treatment period } 1 \# \\
14 \text { (up to } 18 \text { ) days }\end{array}$ & $\begin{array}{c}\text { Washout } \\
\text { period }\end{array}$ & $\begin{array}{l}\text { Treatment period } 2^{\#} \\
14 \text { (up to 18) days }\end{array}$ & $\begin{array}{c}\text { Washout } \\
\text { period }\end{array}$ & $\begin{array}{c}\text { Treatment period 3\# } \\
14 \text { (up to 18) days }\end{array}$ & \\
\hline Sequence $1, n=6$ & \multirow{6}{*}{$\begin{array}{c}\text { Screen } \\
\text { period } \\
14 \text { days }\end{array}$} & \multirow{6}{*}{\begin{tabular}{|l} 
Run-in \\
period \\
14 days
\end{tabular}} & $\begin{array}{l}\text { Placebo a.m. } \\
\text {-IND/GLY/MF p.m. }\end{array}$ & \multirow{5}{*}{$\begin{array}{l}14-21 \\
\text { days }\end{array}$} & $\begin{array}{l}\text { IND/GLY/MF a.m. } \\
\text {-Placebo p.m. }\end{array}$ & \multirow{5}{*}{$\begin{array}{c}14-21 \\
\text { days }\end{array}$} & $\begin{array}{l}\text { Placebo a.m. } \\
\text {-Placebo p.m. }\end{array}$ & Follo \\
\hline Sequence $2, n=6$ & & & $\begin{array}{l}\text { IND/GLY/MF a.m. } \\
\text {-Placebo p.m. }\end{array}$ & & $\begin{array}{l}\text { Placebo a.m. } \\
\text {-IND/GLY/MF p.m. }\end{array}$ & & $\begin{array}{l}\text { Placebo a.m. } \\
\text {-Placebo p.m. }\end{array}$ & \\
\hline Sequence $3, n=6$ & & & $\begin{array}{l}\text { Placebo a.m. } \\
\text {-Placebo p.m. }\end{array}$ & & $\begin{array}{l}\text { IND/GLY/MF a.m. } \\
\text {-Placebo p.m. }\end{array}$ & & $\begin{array}{l}\text { Placebo a.m. } \\
\text {-IND/GLY/MF p.m. }\end{array}$ & $\begin{array}{l}\text { End of } \\
\text { study } \\
\text { visit }\end{array}$ \\
\hline Sequence $4, n=6$ & & & $\begin{array}{l}\text { Placebo a.m. } \\
\text {-Placebo p.m. }\end{array}$ & & $\begin{array}{l}\text { Placebo a.m. } \\
\text {-IND/GLY/MF p.m. }\end{array}$ & & $\begin{array}{l}\text { IND/GLY/MF a.m. } \\
\text {-Placebo p.m. }\end{array}$ & $\begin{array}{c}\text { vist } \\
\text { within } \\
1-7\end{array}$ \\
\hline Sequence $5, n=6$ & & & $\begin{array}{l}\text { Placebo a.m. } \\
\text {-IND/GLY/MF p.m. }\end{array}$ & & $\begin{array}{l}\text { Placebo a.m. } \\
\text {-Placebo p.m. }\end{array}$ & & $\begin{array}{l}\text { IND/GLY/MF a.m. } \\
\text {-Placebo p.m. }\end{array}$ & days \\
\hline Sequence $6, n=6$ & & & $\begin{array}{l}\text { IND/GLY/MF a.m. } \\
\text {-Placebo p.m. }\end{array}$ & & $\begin{array}{l}\text { Placebo a.m. } \\
\text {-Placebo p.m. }\end{array}$ & & $\begin{array}{l}\text { Placebo a.m. } \\
\text {-IND/GLY/MF p.m. }\end{array}$ & \\
\hline
\end{tabular}

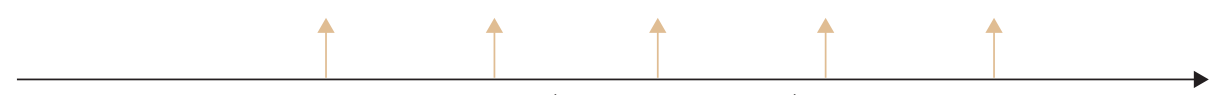

Total study duration 13 (to 19 weeks maximum) per patient

$\downarrow$ Spirometry for eligibility $\quad \downarrow$ Spirometry for treatment effect $\quad$ A Check patient wellbeing (by phone call)

b)

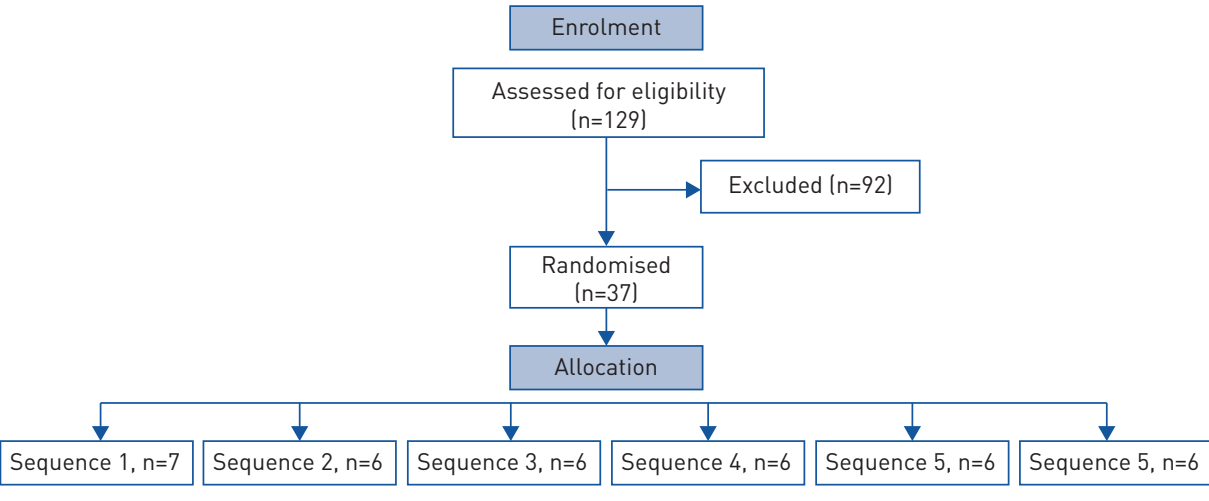

Follow-up

\begin{tabular}{|c|c|c|c|c|}
\hline \multirow[t]{3}{*}{ Treatment period 1} & $\begin{array}{l}\text { Received IND/GLY/MF a.m. } \\
\text { in treatment period } 1(n=12)\end{array}$ & $\begin{array}{l}\text { Received IND/GLY/MF p.m. } \\
\text { in treatment period } 1(n=13)\end{array}$ & $\begin{array}{l}\text { Received placebo in } \\
\text { treatment period } 1(n=12)\end{array}$ & $\begin{array}{l}\text { Total } \\
(\mathrm{n}=37)\end{array}$ \\
\hline & $\begin{array}{l}\text { Completed, } \mathrm{n}=12(100.0 \%) \\
\text { Discontinued, } \mathrm{n}=0(0.0 \%)\end{array}$ & $\begin{array}{l}\text { Completed, } n=13(100.0 \%) \\
\text { Discontinued, } n=0(0.0 \%)\end{array}$ & $\begin{array}{l}\text { Completed, } n=10(83.3 \%) \\
\text { Discontinued }, \mathrm{n}=2(16.7 \%)\end{array}$ & $\begin{array}{l}\text { Completed, } n=35(94.6 \%) \\
\text { Discontinued, } n=2(5.4 \%)\end{array}$ \\
\hline & & Washout & & \\
\hline \multirow[t]{3}{*}{ Treatment period 2} & $\begin{array}{l}\text { Received IND/GLY/MF a.m. } \\
\text { in treatment period } 2 \text { ( } n=13)\end{array}$ & $\begin{array}{l}\text { Received IND/GLY/MF p.m. } \\
\text { in treatment period } 2(n=10)\end{array}$ & $\begin{array}{l}\text { Received placebo in } \\
\text { treatment period } 2(n=12)\end{array}$ & $\begin{array}{l}\text { Total } \\
(n=35)\end{array}$ \\
\hline & $\begin{array}{l}\text { Completed, } n=13(100.0 \%) \\
\text { Discontinued, } n=0(0.0 \%)\end{array}$ & $\begin{array}{l}\text { Completed, } n=10(100.0 \%) \\
\text { Discontinued, } n=10(0.0 \%)\end{array}$ & $\begin{array}{l}\text { Completed, } n=12(100.0 \%) \\
\text { Discontinued, } n=0(0.0 \%)\end{array}$ & $\begin{array}{c}\text { Completed, } n=35(100.0 \%) \\
\text { Discontinued, } n=0(0.0 \%)\end{array}$ \\
\hline & & Washout & & \\
\hline \multirow[t]{2}{*}{ Treatment period 3} & $\begin{array}{l}\text { Received IND/GLY/MF a.m. } \\
\text { in treatment period } 3(n=10)\end{array}$ & $\begin{array}{l}\text { Received IND/GLY/MF p.m. } \\
\text { in treatment period } 3(n=12)\end{array}$ & $\begin{array}{l}\text { Received placebo in } \\
\text { treatment period } 3(n=13)\end{array}$ & $\begin{array}{l}\text { Total } \\
(n=35)\end{array}$ \\
\hline & $\begin{array}{l}\text { Completed, } n=10(100.0 \%) \\
\text { Discontinued, } n=0(0.0 \%)\end{array}$ & $\begin{array}{l}\text { Completed, } n=12(100.0 \%) \\
\text { Discontinued, } n=10(0.0 \%)\end{array}$ & $\begin{array}{l}\text { Completed, } n=12(92.3 \%) \\
\text { Discontinued }^{+}, n=1(7.7 \%)\end{array}$ & $\begin{array}{l}\text { Completed, } n=34(97.1 \%) \\
\text { Discontinued, } n=1(2.9 \%)\end{array}$ \\
\hline
\end{tabular}

FIGURE 1 Study design and participant inclusion. a) Study design. This was a randomised, placebo-controlled, double-blind, six-sequence, three-period, crossover study. b) Study disposition. Of 129 screened for enrolment in this study, 37 patients were randomised to one of six treatment sequences (each consisting of three treatment periods) in an allocation ratio of 1:1:1:1:1:1. For each sequence, al six patients were planned to be randomised; b) as 37 patients were randomised, sequence 1 contained seven patients. 34 patients completed all three treatment periods. IND: indacaterol acetate; GLY: glycopyrronium bromide; MF: mometasone furoate. \#: primary end-point mean forced expiratory volume in $1 \mathrm{~s}\left(\mathrm{FEV}_{1}\right)(\mathrm{L})$ (area under the curve from 0 to $\left.24 \mathrm{~h}\right) ;{ }^{~}$ : two patients discontinued from the study during treatment period 1 due to subject/guardian decision; ${ }^{+}$: one patient experienced an asthma exacerbation and discontinued from the study on the first day of treatment period 3. 


\section{TABLE 1 Definition of treatment sequences}

Treatment period 1

Treatment period 2

Treatment period 3

\begin{tabular}{llll}
\hline 1 & A & B & C \\
2 & B & A & C \\
3 & C & B & A \\
4 & C & A & B \\
5 & A & C & A \\
6 & B & C &
\end{tabular}

A: indacaterol acetate (IND)/glycopyrronium bromide (GLY)/mometasone furoate (MF) evening dose: placebo (a.m.) and IND/GLY/MF (p.m.); B: IND/GLY/MF morning dose: IND/GLY/MF (a.m.) and placebo (p.m.); C: placebo: placebo (a.m.) and placebo (p.m.).

Adherence to the intake of study drug and the need of rescue medication at home was monitored closely by reviewing the patient e-diary in which all patients were instructed to record the details pertaining to administration each day in the morning and in the evening. In addition, compliance was assessed by the investigator and/or study personnel at each visit using capsule counts and information provided by the patient.

\section{Statistical analysis}

The safety analysis set included all patients who received at least one dose of IND/GLY/MF and descriptive safety statistics are presented. The pharmacodynamic (PD) analysis set included all patients with any available PD data, who received any dose of study drug and experienced no protocol deviations with relevant impact on PD data. The primary and secondary analyses included all patients in the PD analysis set.

The primary variable was the weighted mean $\mathrm{FEV}_{1}$ over $24 \mathrm{~h}\left(\mathrm{AUC}_{0-24 \mathrm{~h}}\right)$ following 14 days of treatment with IND/GLY/MF dosed in the morning, IND/GLY/MF dosed in the evening and placebo. The weighted mean (least square (LS) mean) was calculated as the $\mathrm{AUC}_{0-24 \mathrm{~h}}$ divided by the time interval (time of the first observation - time of the last observation) for each patient. The primary variable was determined for each patient on day 14 of each treatment using the linear trapezoidal rule. Data for the primary and secondary end-points were analysed using a linear mixed model. The model included period, treatment (IND/GLY/MF morning, IND/GLY/MF evening, placebo) and sequence as fixed effect factors. The patient effect was assumed to be random. The Kenward-Roger approximation was used to estimate denominator degrees of freedom. From these analyses, point estimates and their associated $90 \%$ confidence intervals were constructed for each treatment. The difference between adjusted LS means and the corresponding two-sided $90 \%$ confidence interval for a.m. dose versus placebo, p.m. dose versus placebo and a.m. versus p.m. dosing were also evaluated within the linear mixed model.

The sample size calculation is described in the supplementary material.

Statistical analyses were performed by Novartis Institutes for Biomedical Research, Switzerland and Novartis Healthcare, India using SAS software (version 9.4; SAS Institute, Cary, NC, USA).

\section{Results}

\section{Participant characteristics}

Of 129 patients screened for inclusion, 37 eligible patients were randomised to one of the six treatment sequences. Of the 37 eligible patients randomised in this study, 35 patients completed treatment period 1 (figure 1b). Two patients receiving placebo discontinued the study (subject/guardian decision) during treatment period 1 on day 1 and day 14, respectively. All 35 patients who entered treatment period 2 completed the treatment period as planned. Of the 35 patients who completed treatment period 2, 34 patients entered and completed treatment period 3. One patient receiving placebo discontinued the study prior to entering treatment period 3 due to an asthma exacerbation (figure $1 b$ ).

Patient demographics and baseline characteristics are summarised in table 2.

At baseline, all patients were receiving maintenance daily treatment with low- (83.8\%) or medium-dose (16.2\%) ICS (table 2). Patients had a mean \pm SD pre-dose $\mathrm{FEV}_{1} 75.8 \pm 9.04 \%$ of predicted normal (table 2). Mean reversibility to SABA was $18.9 \%$ (range 12-52\%) (table 2). 


\begin{tabular}{|c|c|}
\hline Participants & 37 \\
\hline Age years & $46.0(18-72)$ \\
\hline Male & $21(56.8)$ \\
\hline Body mass index $\mathrm{kg} \cdot \mathrm{m}^{-2}$ & $26.2 \pm 4.67$ \\
\hline Blood eosinophils $\times 10^{9}$ cells $\cdot \mathrm{L}^{-1}$ & $0.242 \pm 0.1588$ \\
\hline \multicolumn{2}{|l|}{ Race } \\
\hline White & $35(94.6)$ \\
\hline Other & $2(5.4)$ \\
\hline \multicolumn{2}{|l|}{ Screening ICS category } \\
\hline Low-dose & 31 (83.8) \\
\hline Medium-dose & $6(16.2)$ \\
\hline Pre-bronchodilator FEV $\mathrm{V}_{1} \mathrm{~L}$ & $2.9 \pm 0.72$ \\
\hline Post-bronchodilator FEV $\mathrm{F}_{1} \mathrm{~L}$ & $3.4 \pm 0.81$ \\
\hline $\mathrm{FEV}_{1}$ pre-dose $\%$ predicted & $75.8(60-96)$ \\
\hline Reversibility L & $0.5 \pm 0.21$ \\
\hline Reversibility \% & $18.9(12-52)$ \\
\hline Baseline morning" ${ }^{\#}$ PEF L.min ${ }^{-1}$ & $422.4 \pm 107.42$ \\
\hline Baseline evening ${ }^{\#}$ PEF L. $\min ^{-1}$ & $454.9 \pm 107.51$ \\
\hline
\end{tabular}

\section{Efficacy outcomes}

Effect of IND/GLY/MF dosing time on FEV $\left(A \cup C_{0-24 h}\right)$

14 days of IND/GLY/MF treatment significantly improved weighted mean $\mathrm{FEV}_{1}\left(\mathrm{AUC}_{0-24 \mathrm{~h}}\right)$ compared with placebo, irrespective of time of dosing. LS weighted mean $\mathrm{FEV}_{1}\left(\mathrm{AUC}_{0-24 \mathrm{~h}}\right)$ after 14 days of IND/ GLY/MF a.m. dosing was 3.43 L (90\% CI 3.172-3.689 L), and 3.44 L (90\% CI 3.178-3.694 L) after 14 days of IND/GLY/MF p.m. dosing. Patients receiving placebo for 14 days had a substantially lower weighted mean $\mathrm{FEV}_{1}\left(\mathrm{AUC}_{0-24 \mathrm{~h}}\right)$ of $2.82 \mathrm{~L}(90 \% \mathrm{CI} 2.562-3.080 \mathrm{~L})$. This was consistent with a LS means difference of $610 \mathrm{~mL}$ (90\% CI 538-681 mL) with a.m. dosing of IND/GLY/MF and $615 \mathrm{~mL}$ (90\% CI 544-687 mL) with p.m. dosing of IND/GLY/MF versus placebo (figure 2).

A negligible difference in weighted mean $\mathrm{FEV}_{1}\left(\mathrm{AUC}_{0-24 \mathrm{~h}}\right)$ was observed between IND/GLY/MF morning and evening dose $(-6 \mathrm{~mL}, 90 \% \mathrm{CI}-76-65 \mathrm{~mL} ;<1 \%)$.

Post hoc analyses directly compared $24 \mathrm{~h}$ post-dose $\mathrm{FEV}_{1}$ (trough $\mathrm{FEV}_{1}$ ) between IND/GLY/MF a.m. and p.m. dosing after 14 days of treatment. No difference was observed in mean 24 h post-dose $\mathrm{FEV}_{1}$ between IND/GLY/MF morning and evening dosing ( $8.7 \mathrm{~mL}, 90 \% \mathrm{CI}-60.4-77.8 \mathrm{~mL})$.

End-point

Treatment effect: test versus ref. (in $\mathrm{mL}$ ) Difference $(90 \% \mathrm{CI})$

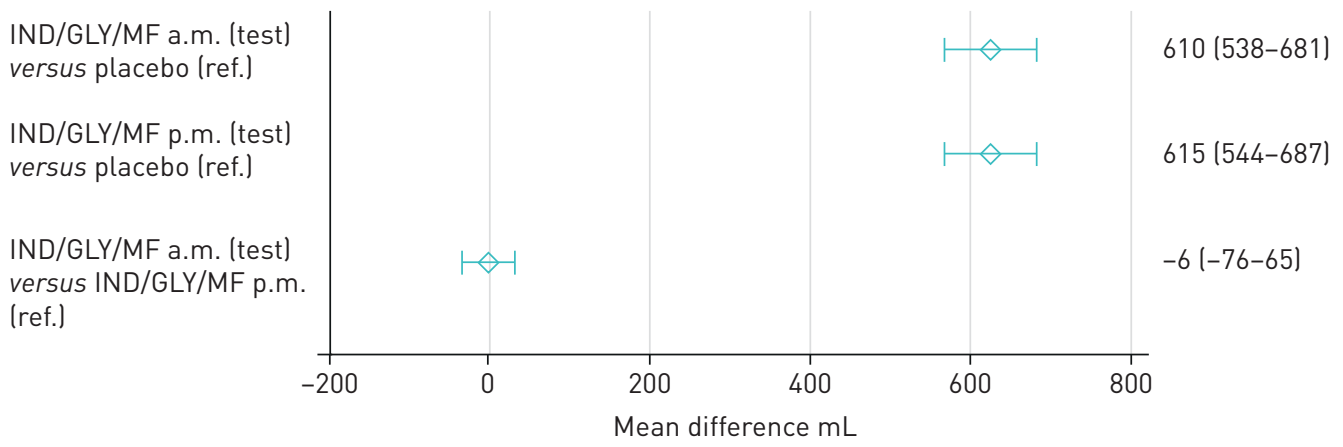

FIGURE 2 Effect of morning or evening dosing of inhaled indacaterol acetate (IND)/glycopyrronium bromide $(G L Y) /$ mometasone furoate (MF) on weighted mean forced expiratory volume in $1 \mathrm{~s}\left(\mathrm{FEV}_{1}\right)$ larea under the curve from 0 to $24 \mathrm{~h}\left(\mathrm{AUC}_{0-24 \mathrm{~h}}\right)$ ) versus placebo (pharmacodynamics (PD) analysis set). Comparison of morning or evening dosing of IND/GLY/MF on weighted mean $\mathrm{FEV}_{1}(\mathrm{~mL})\left(\mathrm{AUC}_{0-24 \mathrm{~h}}\right)$ with placebo in the PD analysis set. Parameters were analysed using a mixed model adjusting for period, treatment and sequence as fixed effect factors, and patient as a random effect. Data are presented as least squares means treatment difference $(90 \% \mathrm{CI})$ compared with placebo. ref: reference. 
TABLE 3 Comparison of peak expiratory flow (PEF) measured in the morning and evening after 14 days of treatment (pharmacodynamics analysis set)

PEF L- $\min ^{-1}$

LS means $(90 \% \mathrm{CI})$

$489.6(456.2-523.1)$ versus 417.5 (384.1-450.9)

504.4 (471.0-537.9) versus 417.5 (384.1-450.9)

$489.6(456.2-523.1)$ versus $504.4(471.0-537.9)$

522.0 (488.7-555.4) versus 449.0 (415.7-482.3)

$507.7(474.3-541.0)$ versus 449.0 (415.7-482.3)

522.0 (488.7-555.4) versus 507.7 (474.3-541.0)

LS means difference $(90 \% \mathrm{Cl})$

$72.1(61.3-82.9)$

$86.9(76.1-97.8)$

$-14.8(-25.6--4.1)$

$73.1(61.9-84.2)$

$58.7(47.5-69.9)$

$14.4(3.3-25.5)$

$\mathrm{n}=35$, unless otherwise stated. Morning PEF assessments were performed $24 \mathrm{~h}$ after the last morning dose and $12 \mathrm{~h}$ after the last evening dose. Analogously, the evening PEF assessments were performed $24 \mathrm{~h}$ after the last evening dose and $12 \mathrm{~h}$ after the last morning dose. LS: least squares; IND: indacaterol acetate; GLY: glycopyrronium bromide; MF: mometasone furoate. " : $n=36$.

Effect of dosing time of IND/GLY/MF on PEF

Mean morning PEF (measured pre-dose on the morning of day 15 of each treatment period) was significantly improved by IND/GLY/MF dosed in the morning and the evening (LS means difference $72.1 \mathrm{~L} \cdot \mathrm{min}^{-1}\left(90 \%\right.$ CI $\left.61.3-82.9 \mathrm{~L} \cdot \mathrm{min}^{-1}\right)$ and $86.9 \mathrm{~L} \cdot \mathrm{min}^{-1}\left(90 \% \mathrm{CI} 76.1-97.8 \mathrm{~L} \cdot \mathrm{min}^{-1}\right)$, respectively versus placebo) (table 3).

Similarly, mean evening PEF (measured on the evening of day 15 of each treatment period) was significantly improved by IND/GLY/MF morning dose (LS means difference $73.1 \mathrm{~L} \cdot \mathrm{min}^{-1}$, 90\% CI 61.9-84.2 L·min ${ }^{-1}$ ) and evening dose (58.7 L·min ${ }^{-1}, 90 \% \mathrm{CI}$ 47.5-69.9 L·min ${ }^{-1}$ ) versus placebo (table 3).

There were negligible differences in overall PEF values between morning and evening dosing (versus placebo) (figure 3). With IND/GLY/MF dosed in the morning, the next morning pre-dose PEF was lower compared with dosing in the evening $\left(-14.8 \mathrm{~L} \cdot \mathrm{min}^{-1}, 90 \% \mathrm{CI}-25.6-4.1 \mathrm{~L} \cdot \mathrm{min}^{-1}\right)$. Analogously, pre-dose PEF was higher in the evening with morning dosing than with evening dosing $\left(+14.4 \mathrm{~L} \cdot \mathrm{min}^{-1}, 90 \% \mathrm{CI}\right.$ 3.3-25.5 L·min ${ }^{-1}$ ).

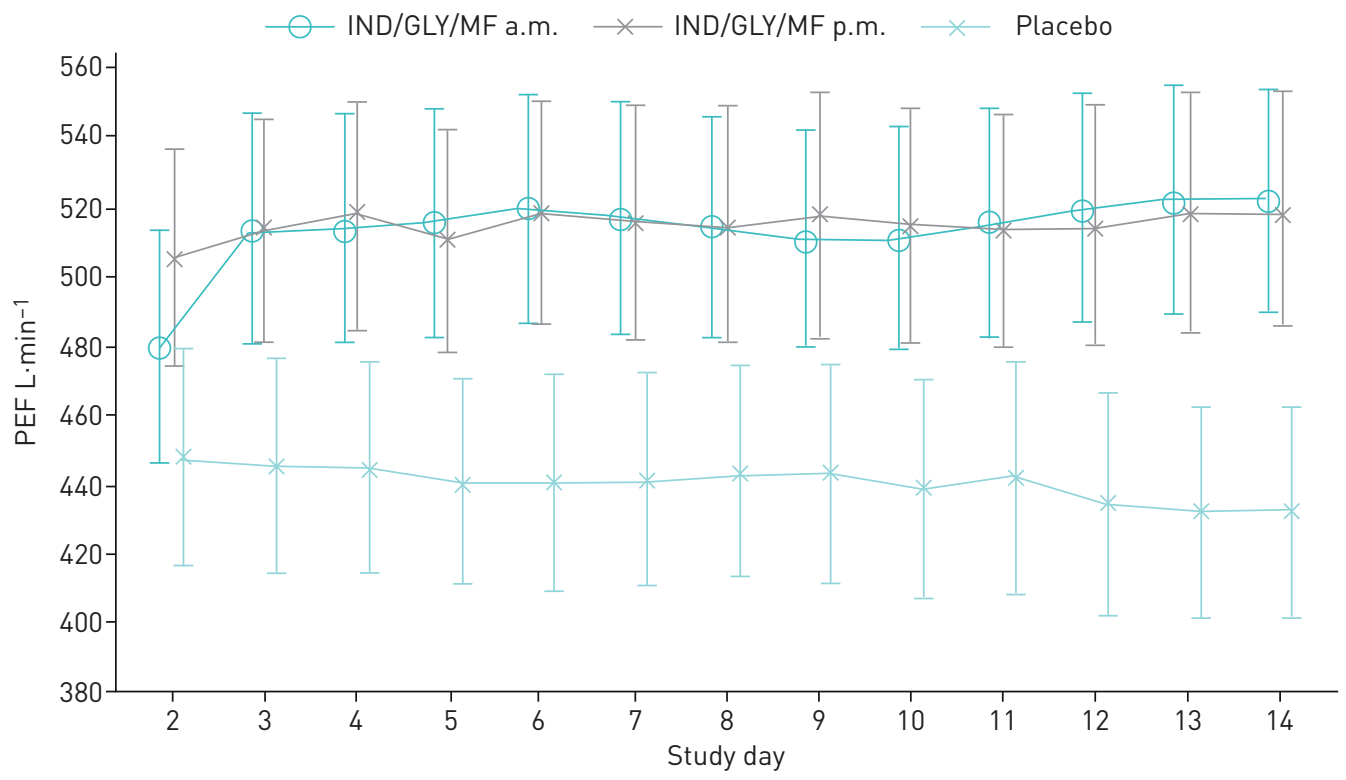

FIGURE 3 Effect of indacaterol acetate (IND)/glycopyrronium bromide (GLY)/mometasone furoate (MF) on overall mean peak expiratory flow (L. $\left.\mathrm{min}^{-1}\right)(90 \% \mathrm{CI})$ over days 2-14 by treatment (pharmacodynamics analysis set). Parameters were calculated using a mixed-effects model including period, treatment (IND/GLY) MF morning, IND/GLY/MF evening, placebo), and sequence as fixed effects. Note: if a treatment period for an individual patient exceeded 14 days, the patient's peak expiratory flow (PEF) values contributed only up to day 14 for the respective period. 


\section{Safety and tolerability}

Safety and tolerability were assessed in the safety analysis set $(n=37)$. No serious adverse events, deaths or new safety findings for IND/GLY/MF were reported during this study. The incidence of treatment-emergent adverse events affecting $>5 \%$ of patients by treatment group is available in table 4 . The safety and tolerability profiles of IND/GLY/MF were comparable between a.m. and p.m. dosing and were similar to placebo (table 4). Two patients discontinued in the placebo period due to subject/guardian decision and one patient discontinued during a washout period due to an asthma exacerbation of moderate severity.

Two patients experienced an adverse event graded as severe: one bacterial food poisoning (day 15 during the IND/GLY/MF p.m. dosing period) and one case of influenza (day 9 during IND/GLY/MF p.m. dosing period). These were deemed unrelated to the study treatment by the investigator and did not lead to discontinuation of the patients from the study.

Rescue medication use details are available for 35 patients. The number of patients who did not take rescue medication (SABA) in the last 7 days in the respective periods were 24 (71\%) with IND/GLY/MF morning dosing, 24 (71\%) with IND/GLY/MF evening dosing and 10 (29\%) with placebo. The odds ratio of being rescue medication free with morning dosing versus placebo was 11.5 (95\% CI 2.6-50.3; p=0.0015). Evening dosing results were almost identical.

\section{Discussion and conclusions}

The results of this study show that once-daily IND/GLY/MF at $150 \mu \mathrm{g}$ of indacaterol acetate, $50 \mu \mathrm{g}$ of glycopyrronium bromide and $80 \mu \mathrm{g}$ of mometasone furoate (medium ICS dose category) delivered with the Breezhaler device elicits substantial and sustained bronchodilation in patients with asthma receiving ICS at baseline after 14-18 days of treatment, irrespective of the time of dosing (a.m. or p.m.). In addition, the fixed combination was well tolerated overall. These data support the once-daily use of IND/GLY/MF as treatment in patients with asthma.

Evidence generated from randomised controlled trials is supportive of the use of LABA/LAMA/ICS in the treatment of patients with poorly controlled asthma despite the use of ICS and LABA [16]. Tiotropium was tested as an add-on to LABA/ICS treatment in two replicate studies, showing that addition of tiotropium $5 \mu \mathrm{g}$ ( via the Respimat inhalation device) resulted in significant changes in peak $\mathrm{FEV}_{1}$ from baseline compared with placebo (increases of $86 \pm 34 \mathrm{~mL}$ and $154 \pm 32 \mathrm{~mL}$ ) in patients with a mean baseline $\mathrm{FEV}_{1}$ of $62 \%$ predicted [17]. In the 52-week TRIMARAN and TRIGGER studies, twice-daily inhalations of formoterol fumarate (FF)/glycopyrronium (G)/beclometasone dipropionate (BDP) from a single device showed significant improvements of $57 \mathrm{~mL}$ and $73 \mathrm{~mL}$ in pre-dose $\mathrm{FEV}_{1}$, respectively, versus $\mathrm{FF} / \mathrm{BDP}$ [18] The individual lung function contribution of the LABA indacaterol and the LAMA glycopyrronium were not investigated in this clinical trial. To put results into perspective, it is helpful to consider that in large phase 3 trials that investigated IND/MF versus MF alone and IND/GLY/MF versus IND/MF adding IND to $\mathrm{MF}$ increased trough $\mathrm{FEV}_{1}$ by $132-211 \mathrm{~mL}$ after 26 weeks of treatment [19] and adding GLY to IND/ MF increased it by an additional 65-76 $\mathrm{mL}[20]$.

Adherence to treatment is a key element of sustained asthma control. While once-daily dosing has been suggested to improve adherence [21], a patient may prefer a (flexible) time of the day to take his or her

TABLE 4 Incidence of treatment-emergent adverse events by preferred MedDRA term affecting $>5 \%$ of patients (safety analysis set)

\begin{tabular}{|c|c|c|c|c|}
\hline & IND/GLY/MF a.m. & IND/GLY/MF p.m. & Placebo & Total \\
\hline Patients & 35 & 35 & 36 & 37 \\
\hline Number of patients with $\geqslant 1$ adverse event & $18(51.4)$ & $23(65.7)$ & $18(50.0)$ & $32(86.5)$ \\
\hline Headache & $5(14.3)$ & $3(8.6)$ & $7(19.4)$ & $10(27.0)$ \\
\hline Nasopharyngitis & $2(5.7)$ & $2(5.7)$ & $5(13.9)$ & $8(21.6)$ \\
\hline Oropharyngeal pain & $3(8.6)$ & $4(11.4)$ & $2(5.6)$ & $7(18.9)$ \\
\hline Cough & $1(2.9)$ & $2(5.7)$ & $1(2.8)$ & $4(10.8)$ \\
\hline Dysphonia & $2(5.7)$ & $3(8.6)$ & $1(2.8)$ & $4(10.8)$ \\
\hline Asthma & $1(2.9)$ & $1(2.9)$ & $1(2.8)$ & $3(8.1)$ \\
\hline Throat clearing & $1(2.9)$ & $1(2.9)$ & $0(0.0)$ & $2(5.4)$ \\
\hline
\end{tabular}

Data are presented as $\mathrm{n}$ or $\mathrm{n}(\%)$. MedDRA: Medical Dictionary for Regulatory Activities; IND: indacaterol acetate; GLY: glycopyrronium bromide; MF: mometasone furoate. 
medication. Hence, flexibility of dosing, irrespective of the time of day, may further support adherence. Based on the present data, IND/GLY/MF allows this flexibility. In this study, the 2-week run-in period allowed for an assessment of likely study adherence since patients used short-acting rescue medication only, and ensured that those who could not tolerate withdrawal from ICS for a short period of time were not randomised. Since the increases in $\mathrm{FEV}_{1}$ as the primary outcome with morning and evening dosing of IND/GLY/MF versus placebo were substantial and comparable, it is reasonable to assume that adherence was high. The formulation of fixed-dose LABA/LAMA/ICS combinations in a single device may have contributed to a good level of adherence [16].

To benchmark the presented increases in $\mathrm{FEV}_{1}\left(\mathrm{AUC}_{0-24 \mathrm{~h}}\right)$ of $>600 \mathrm{~mL}$ with IND/GLY/MF over placebo, previous reports for LABA/ICS fixed-dose combination effects can be considered. For vilanterol/fluticasone furoate administered using a dry-powder inhaler, increases of $377 \mathrm{~mL}$ and $422 \mathrm{~mL}$ in $\mathrm{FEV}_{1}\left(\mathrm{AUC}_{0-24 \mathrm{~h}}\right)$ following morning and evening dose, respectively, over 14 days versus placebo were observed in a similar population of asthmatic patients aged $18-70$ years with $\mathrm{FEV}_{1}$ of $\geqslant 60 \%$ pred [22]. Furthermore, when these increases are added to those observed in adult asthmatics with baseline $\mathrm{FEV}_{1}$ of $60-85 \%$ pred, the LAMA umeclidinium dosed at 5.6, 31.25, 62.5, 125 or $250 \mu \mathrm{g}$ once daily, or 15.6 or $31.25 \mu \mathrm{g}$ twice daily, administered for 14 days (range $68-121 \mathrm{~mL}$ for increase in $\mathrm{FEV}_{1}\left(\mathrm{AUC}_{0-24 \mathrm{~h}}\right.$ ) over placebo) [23], improvements appeared to be less than those achieved with IND/GLY/MF in the present study. Since comparing observations across studies carries limitations (e.g. differences in drugs and doses used, treatment duration, patient populations), the authors caution against the over-interpretation of these cross-study observations.

PEF is measured twice daily every day and is therefore a reliable, consistent and accurate measure of lung function variation with some correlation to symptoms, even for patients who cannot perform full spirometry manoeuvres. The PEF improvements versus placebo observed with IND/GLY/MF in this study are well above the range $\left(15-20 \mathrm{~L} \cdot \mathrm{min}^{-1}\right)$ suggested to be clinically relevant and perceptible by the patient $[24,25]$. The consistency in PEF over the treatment period suggests good and stable lung function control with IND/GLY/MF in patients with asthma.

The safety and tolerability profile of IND/GLY/MF was similar to placebo. The two severe adverse events of influenza and food poisoning that occurred during this study were deemed unrelated to the study drug by the investigator, and there were no serious adverse events, deaths or new safety findings reported. One patient discontinued the study during the placebo period due to an asthma exacerbation which was treated with prednisolone.

Potential limitations to this study include the relatively short duration of treatment, participants being limited to those with mild to moderate asthma which differs from the labelled indication of IND/GLY/MF, and the rate of adherence to study medication which was self-reported via an electronic diary. While 14 days of treatment cannot give a reliable estimate of asthma control sustained benefits were demonstrated over each IND/GLY/MF treatment period as evidenced by substantial, consistent, and constant PEF improvements compared to placebo (figure 3). Although lack of data on asthma control status can be perceived as a limitation, it should be noted that this is a comparatively small study embedded in the overall development programme of IND/GLY/MF, the results of which have been published previously $[19,20,26]$.

Overall, these results demonstrate that IND/GLY/MF is effective irrespective of time of dosing, and therefore, that this fixed-dose combination can be administered effectively and safely either in the morning or the evening.

Acknowledgements: The authors thank Karine Lheritier (Novartis Pharma, Basel, Switzerland) for input on the statistical analysis of the data. The authors thank Gillian Lavelle, Evelyn Altemeyer and Áine Abautret-Daly (Novartis Product Lifecycle Services, Dublin, Ireland) for providing scientific writing support for this article, which was funded by Novartis Pharma (Basel, Switzerland) in accordance with good publication practice (GPP3) guidelines (www.ismpp.org/ gpp3). D. Singh is supported by the National Institute for Health Research Manchester Biomedical Research Centre.

Conflict of interest: J. Beier reports personal fees from Novartis during the conduct of the study, and personal fees from AstraZeneca, Berlin Chemie/Menarini and Pohl Boskamp outside the submitted work. H. Watz reports grants, personal fees and nonfinancial support from Novartis during the conduct of the study; and grants, personal fees and nonfinancial support from AZ, Berlin Chemie/Menarini, GSK, Chiesi, Bayer and Takeda, outside the submitted work. Z. Diamant reports grants from Novartis during the conduct of the study, and personal fees from Acucort, AstraZeneca, ALK, Aquilon, Boehringer Ingelheim, CSL, HAL Allergy, MSD and Sanofi Genzyme outside the submitted work. J.M. Hohlfeld reports grants paid to his institution from Novartis during the conduct of the study; and consultancy fees from Boehringer Ingelheim, grants paid to his institution from AstraZeneca AB, Novartis, Janssen Pharmaceutica NV, ALK, Boehringer Ingelheim, LETI, GlaxoSmithKline and grants from Sanofi-Aventis, consultancy fees from Merck \& Co, Inc., lecture fees from Novartis, grants paid to his institution from Astellas Pharma and Allergopharma, and lectures fees from HAL, outside the submitted work. D. Singh reports personal fees from AstraZeneca, Boehringer Ingelheim, Chiesi, Cipla, Genentech, GlaxoSmithKline, Glenmark, Gossamerbio, Menarini, Mundipharma, Novartis, Peptinnovate, 
Pfizer, Pulmatrix, Theravance and Verona, outside the submitted work. P. Pinot is an employee of Novartis. I. Jones is an employee of Novartis. H-C. Tillmann is an employee of Novartis.

Support statement: This study was supported by Novartis Pharma AG grant QVM149B2209. Funding information for this article has been deposited with the Crossref Funder Registry.

\section{References}

1 Braido F, Brusselle G, Guastalla D, et al. Determinants and impact of suboptimal asthma control in Europe: The International Cross-sectional and Longitudinal Assessment on Asthma Control (LIAISON) study. Respir Res 2016; 17: 51 .

2 Braido F. Failure in asthma control: reasons and consequences. Scientifica 2013; 2013: 549252.

3 Global Initiative for Asthma. Global Strategy for Asthma Management and Prevention. 2018. Available from: http://ginasthma.org/gina-reports/ Date last accessed: February 15, 2019.

4 Kew KM, Dahri K. Long-acting muscarinic antagonists (LAMA) added to combination long-acting beta -agonists $^{-}$ and inhaled corticosteroids (LABA/ICS) versus LABA/ICS for adults with asthma. Cochrane Database Syst Rev 2016; 1: CD011721.

5 Papi A, Vestbo J, Fabbri L, et al. Extrafine inhaled triple therapy versus dual bronchodilator therapy in chronic obstructive pulmonary disease (TRIBUTE): a double-blind, parallel group, randomised controlled trial. Lancet 2018; 391: 1076-1084.

6 Durrington HJ, Farrow SN, Loudon AS, et al. The circadian clock and asthma. Thorax 2014; 69: 90-92.

7 Durrington HJ, Gioan-Tavernier GO, Maidstone RJ, et al. Time of day affects eosinophil biomarkers in asthma: implications for diagnosis and treatment. Am J Respir Crit Care Med 2018; 198: 1578-1581.

8 Wilkinson M, Maidstone R, Loudon A, et al. Circadian rhythm of exhaled biomarkers in health and asthma. Eur Respir J 2019; 54: 1901068.

9 Beam WR, Weiner DE, Martin RJ. Timing of prednisone and alterations of airways inflammation in nocturnal asthma. Am Rev Respir Dis 1992; 146: 1524-1530.

10 Pincus DJ, Humeston TR, Martin RJ. Further studies on the chronotherapy of asthma with inhaled steroids: the effect of dosage timing on drug efficacy. J Allergy Clin Immunol 1997; 100: 771-774.

11 Altman P, Bergna MA, Garcia GR, et al. Patient perception of Breezhaler and Ellipta device feedback mechanisms in COPD: the ADVANTAGE study. Curr Med Res Opin 2019; 35: 221-227.

12 Buhl R, Banerji D. Profile of glycopyrronium for once-daily treatment of moderate-to-severe COPD. Int J Chron Obstruct Pulmon Dis 2012; 7: 729-741.

13 Wedzicha JA, Decramer M, Ficker JH, et al. Analysis of chronic obstructive pulmonary disease exacerbations with the dual bronchodilator QVA149 compared with glycopyrronium and tiotropium (SPARK): a randomised, double-blind, parallel-group study. Lancet Respir Med 2013; 1: 199-209.

14 Global Initiative for Asthma. Global Strategy for Asthma Management and Prevention. 2017. Available from: http://ginasthma.org/gina-reports/ Date last accessed: June 26, 2017.

15 Miller MR, Hankinson J, Brusasco V, et al. Standardisation of spirometry. Eur Respir J 2005; 26: 319-338.

16 Cazzola M, Puxeddu E, Matera MG, et al. A potential role of triple therapy for asthma patients. Expert Rev Respir Med 2019; 13: 1079-1085.

17 Kerstjens HA, Engel M, Dahl R, et al. Tiotropium in asthma poorly controlled with standard combination therapy. N Engl J Med 2012; 367: 1198-1207.

18 Virchow JC, Kuna P, Paggiaro P, et al. Single inhaler extrafine triple therapy in uncontrolled asthma (TRIMARAN and TRIGGER): two double-blind, parallel-group, randomised, controlled phase 3 trials. Lancet 2019; 394: $1737-1749$.

19 van Zyl-Smit RN, Krüll M, Gessner C, et al. Once-daily mometasone plus indacaterol versus mometasone or twice-daily fluticasone plus salmeterol in patients with inadequately controlled asthma (PALLADIUM): a randomised, double-blind, triple-dummy, controlled phase 3 study. Lancet Respir Med 2020; 8: 987-999.

20 Kerstjens HAM, Maspero J, Chapman KR, et al. Once-daily, single-inhaler mometasone-indacaterolglycopyrronium versus mometasone-indacaterol or twice-daily fluticasone-salmeterol in patients with inadequately controlled asthma (IRIDIUM): a randomised, double-blind, controlled phase 3 study. Lancet Respir Med 2020; 8: $1000-1012$

21 Averell CM, Stanford RH, Laliberté F, et al. Medication adherence in patients with asthma using once-daily versus twice-daily ICS/LABAs. J Asthma 2021; 58: 102-111.

22 Kempsford $\mathrm{RD}$, Oliver A, Bal J, et al. The efficacy of once-daily fluticasone furoate/vilanterol in asthma is comparable with morning or evening dosing. Respir Med 2013; 107: 1873-1880.

23 Lee LA, Briggs A, Edwards LD, et al. A randomized, three-period crossover study of umeclidinium as monotherapy in adult patients with asthma. Respir Med 2015; 109: 63-73.

24 Reddel HK, Taylor DR, Bateman ED, et al. An official American Thoracic Society/European Respiratory Society statement: asthma control and exacerbations: standardizing endpoints for clinical asthma trials and clinical practice. Am J Respir Crit Care Med 2009; 180: 59-99.

25 Santanello NC, Zhang J, Seidenberg B, et al. What are minimal important changes for asthma measures in a clinical trial? Eur Respir J 1999; 14: 23-27.

26 Gessner C, Kornmann O, Maspero J, et al. Fixed-dose combination of indacaterol/glycopyrronium/mometasone furoate once-daily versus salmeterol/fluticasone twice-daily plus tiotropium once-daily in patients with uncontrolled asthma: a randomised, phase IIIb, non-inferiority study (ARGON). Respir Med 2020; 170: 106021. 